\title{
A efetividade do processo de doação de órgãos frente a nova legislação
}

\begin{abstract}
RESUMO I O decreto № 9.175, de 18 de outubro de 2017 trouxe consideráveis e necessárias mudanças ao texto da Lei de Doaação de Órgãos, visando dar maior rapidez e garantia para que os procedimentos sejam realizados com pleno êxito, levando-se em consideração que o Brasil figura em posição privilegiada na lista dos países que mais realizam transplantes no mundo. Por este motivo, este estudo tem por objetivo verificar a efetividade da agilização da doação de órgãos frente a nova legislação brasileira. Utilizou-se como metodologia a revisão integrativa, com busca nos bancos de dados BVS, SciELO e LILACS, que levou a seleção de 10 artigos que analisados levaram a criação de três categorias temáticas: A Conduta da enfermagem frente ao Provável Doador; Fatores que levam a doação ou não de órgãos e A Efetividade da Nova Legislação na Agilização da Doação de Órgãos. Concluiu-se que fica nítida a necessidade de verificação mais aprofundada junto aos órgãos competentes, que forneçam dados a respeito da efetivação da doação de órgãos e que aumentem o número de publicações informando e auxiliando o profissional da saúde na minimização de filas e na melhoria de qualidade de vida daquele que tanto almeja uma chance de transplante.
\end{abstract}

Palavras-chaves: Doação de Órgãos; Nova Legislação; Agilização; Enfermagem.

\begin{abstract}
Decree No. 9,175 of October 18, 2017 brought considerable and necessary changes to the text of the Organ Donation Law, with a view to speeding up and ensuring that procedures are carried out with full success, taking into account that the Brazil is in a privileged position in the list of countries that perform the most transplants in the world. For this reason, this study aims to verify the effectiveness of the agility of organ donation in front of the new Brazilian legislation. The integrative review was used as a methodology, with a search in the VHL, SciELO and LILACS databases, which led to the selection of 10 articles that analyzed led to the creation of three thematic categories: Nursing Conduct versus Probable Donor; Factors that lead to donation or not of organs and The Effectiveness of New Legislation in Streamlining Organ Donation. It was concluded that there is a clear need for more detailed verification to the competent organs, to provide data regarding the effectiveness of organ donation and to increase the number of publications informing and assisting the health professional in minimizing queues and improving quality of life of those who long for a chance of transplantation.
\end{abstract}

Keywords: Organ Donation; New Legislation; Streamlining; Nursing.

RESUMEN | El Decreto No. 9.175, de 18 de octubre de 2017, trajo cambios considerables y necesarios al texto de la Ley de Donación de Órganos, con el objetivo de proporcionar mayor velocidad y garantía para que los procedimientos se lleven a cabo con pleno éxito, teniendo en cuenta que Brasil se encuentra en una posición privilegiada en la lista de países que realizan más trasplantes en el mundo. Por esta razón, este estudio tiene como objetivo verificar la efectividad de la donación racionalizada de órganos en virtud de la nueva legislación brasileña. La revisión integradora se utilizó como metodología, con una búsqueda en las bases de datos de BVS, SciELO y LILACS, lo que condujo a la selección de 10 artículos que analizados condujeron a la creación de tres categorías temáticas: la conducta de enfermería hacia el donante probable; Factores que conducen a la donación de órganos o no y La efectividad de la nueva legislación en la racionalización de la donación de órganos. Se concluyó que existe una clara necesidad de una verificación más profunda con los organismos competentes, para proporcionar datos sobre la efectividad de la donación de órganos y para aumentar el número de publicaciones que informan y ayudan al profesional de la salud a minimizar las colas y mejorar calidad de vida de quienes anhelan una posibilidad de trasplante.

Descriptores: Donación de Órganos; Nueva Legislación; Racionalización; Enfermería.

\section{Vanessa Souza Silva}

Enfermeira. Especialista em Terapia Intensiva Adulto. Universidade Castelo Branco. RJ/Brasil.

\section{Cinthia Umbelino Ferreira de Souza}

Enfermeira. Especialista em Estomaterapia e saúde Pública com ênfase em ESF. Pós-graduanda em Terapia Intensiva. Universidade Castelo Branco. RJ/Brasil.

\section{Maria Regina Bernardo da Silva}

Enfermeira. Mestre em saúde da Família. Docente da Universidade Castelo Branco. RJ/Brasil.

\section{Sandra Conceição Ribeiro Chicharo}

Enfermeira. Doutoranda pela Universidade Federal Fluminense. Coordenadora da Graduação da Universidade Castelo Branco. RJ/Brasil.

\section{Priscilla Passarelli Tostes}

Enfermeira. Especialista em Captação, Doação e Transplante de Órgãos e Tecidos. Supervisora da Equipe Técnica da Central Nacional de Transplantes do Ministério da Saúde. RJ/Brasil.

\section{Daniel Ribeiro Soares de Souza}

Enfermeiro. Mestre em saúde e Tecnologia Hospitalar. Especialista em Captação, Doação e Transplante de Órgãos e Tecidos. Docente da Universidade Castelo Branco. Enfermeiro da Coordenação Geral de Transplantes (HUCFF/UFRJ). RJ/Brasil. 
A doação de órgãos para transplantes se realiza por meio da extração de órgãos vivos de corpos humanos sem vida e de órgãos vivos de doadores conscientes, em que a remoção não ocasionaria a morte do doador ${ }^{(1)}$.

Desta forma, o transplante pode ser entendido como o ato de retirada ou remoção de órgãos, tecidos ou partes de um ser, esteja ele vivo ou morto, para o seu aproveitamento com finalidade terapêutica ${ }^{(2)}$.

A doação pode ser de órgãos (rim, fígado, coração, pâncreas e pulmão) ou de tecidos (córnea, pele, ossos, válvulas cardíacas, cartilagem, medula óssea e sangue de cordão umbilical). No caso de órgãos, como o rim, parte do fígado, do pulmão e da medula óssea, ela pode ser feita em vida, mas os demais só podem ser doados após a morte do doador ${ }^{(3)}$.

Neste processo de doação e captação de órgãos, a diferença básica entre a vida e a morte reside na avaliação neurológica do doador, uma vez que os indivíduos com morte encefálica fornecem seus órgãos para substituírem aqueles ineficientes de outro paciente, o receptor. Sob esse aspecto, é importante ressaltar que, apesar do avanço tecnológico ocorrido nesta área, ainda existem divergências quanto à linha tênue que separa a vida e a morte, favorecendo, por conseguinte, o desenvolvimento de conflitos de ordem bioética que atingem doadores, familiares, receptores e, inclusive, os profissionais de saúde ${ }^{(1)}$.

A doação de órgãos no Brasil aumentou no início de 2017 em relação ao ano anterior, sendo que o número de doadores em todo o país cresceu quase doze por cento (11,8\%). Aumentou também o número de transplantes de rim $(5,8 \%)$, fígado $(7,4 \%)$ e córneas $(7,6 \%)$, mas caíram os de coração $(-3,6 \%)$, pulmão $(-6,5 \%)$ e pâncreas $(-6,0 \%)$.
Já no final do mesmo ano, a taxa de doadores efetivos cresceu $14 \%$, atingindo 16,6 pmp, esse acréscimo permitiu alcançar o objetivo previsto em 2015 para esse ano (16,6 pmp), e decorreu do aumento de $3,8 \%$ na taxa de notificação de potenciais doadores (51,6 pmp) e de $10,2 \%$ na taxa de efetivação de doadores (32,4\%). Destacaram-se Santa Catarina $(40,8$ pmp) com aumento de 10,9\% e Paraná (38,0 pmp) com incremento de $26,2 \%$, únicos estados que ultrapassaram os 30 doadores pmp e apenas Santa Catarina efetivou $50 \%$ dos potenciais doadores ${ }^{(4)}$.

Segundo o Ministério da Saúde, cerca de 95\% dos transplantes de órgãos no país são financiados pelo Sistema Único de Saúde (SUS). No sistema público, os pacientes recebem assistência integral e gratuita, com exames preparatórios, cirurgia, acompanhamento e medicamentos pós-transplante. Atualmente, segundo o ministério, a fila de espera por um transplante tem 41.122 pessoas $^{(5)}$.

Observa-se uma grande dificuldade no processo de doação de órgãos. Embora o papel das unidades notificadoras, locais onde são notificados os potenciais doadores, seja de grande relevância, questões como a falta de um ambiente reservado para a realização das entrevistas familiares, equipe acolhedora e profissionais capacitados, representam obstáculos a serem transpostos pelo país que possui o maior sistema público de transplantes do mundo. Os manejos das situações difíceis demonstram a necessidade de recursos não somente técnicos, mas principalmente, próprios/subjetivos de enfrentamento, estando a relação com as emoções em destaque, seja com os familiares do potencial doador, seja com a equipe da unidade notificadora ou mesmo consigo na atividade da entrevista familiar ${ }^{(6)}$.

Frente a estes fatos, a Lei de Transplantes no Brasil, que trata da disposi- ção gratuita de tecidos, órgãos e partes do corpo humano, in vita ou post mortem, Lei n. ${ }^{\circ}$ 9.434/1997, desde sua edição, vem sendo alterada para se adequar às novas tecnologias disponíveis e proporcionar ao homem as melhores condições de saúde e longevidade ${ }^{(7)}$.

Sua última alteração foi efetuada pelo Decreto n. ${ }^{\circ}$ 9.175, de 18 de outubro de 2017, que trouxe consideráveis e necessárias mudanças ao texto original, visando dar maior rapidez e garantia para que os procedimentos sejam realizados com pleno êxito, levando-se em consideração que o Brasil figura em posição privilegiada na lista dos países que mais realizam transplantes no mundo ${ }^{(8)}$.

Entre as mudanças realizadas pelo decreto citado, está o diagnóstico com base nos critérios definidos em resolução pelo Conselho Federal de Medicina (CFM), o que teoricamente agilizaria o processo de doação de órgãos ${ }^{(8)}$.

Neste ponto, iniciou-se a motivação que leva ao foco desta pesquisa, pois questionou-se se em face à nova legislação promulgada, se na prática, o processo de doação de órgãos seria realmente agilizado, já que houve mudanças substanciais nos prazos que englobam desde o diagnóstico de morte encefálica, passando pela autorização familiar, até sua efetiva retirada.

Esse processo é um fenômeno complexo e que o enfermeiro interage com diversas pessoas e exerce um papel muito importante dentro da equipe de saúde, necessitando estar adequadamente informado, não somente sobre as etapas do processo, mas quanto à legislação que dita as regras básicas de diagnóstico, autorização e ética, fatos que justificam a importância do tema a ser pesquisado.

O Conselho Federal de Enfermagem (COFEN) preconiza ao enfermeiro responsável pelo processo de doação de órgãos o planejamento, execução, coordenação, supervisão e avaliação dos procedimentos de Enfermagem 
prestados ao doador. Esse profissional também fica responsável por planejar e implementar ações que visem a otimização de doação e captação de órgãos e tecidos para transplante ${ }^{(9)}$.

Portanto, o enfermeiro desempenha papel essencial no estabelecimento de um programa de transplante de sucesso. Sua atuação vai desde educar a respeito da doação de órgãos e tecidos até a manutenção do potencial doador e provisão de cuidados aos pacientes submetidos a transplante ${ }^{(3)}$.

O texto da nova lei de transplantes no Brasil trouxe diversas alterações com o intuito de agilizar o processo de doação de órgãos, desde o diagnóstico de morte encefálica até sua entrega ao receptor. Surge assim a necessidade de verificar índices para que se possa comparar os tempos utilizados anteriormente, para com aqueles utilizados atualmente, após sua instauração, para que se possa saber se na prática os objetivos desta lei estão sendo alcançados $^{(8)}$.

Considerando as atribuições do enfermeiro preconizadas pelo Conselho de Enfermagem, torna-se necessário ao enfermeiro estar preparado e atualizado para a atuação no processo de doação de órgãos. Desta forma, a pesquisa auxilia na coleta de informações essenciais à complementação de sua educação e, consequente, inserção no mercado de trabalho.

Espera-se com esta pesquisa contribuir na produção de material que traga informações pertinentes e atualizadas aos profissionais da saúde quanto à nova legislação brasileira de doação de órgãos que auxiliam na agilização do processo.

Quanto ao meio acadêmico, espera-se auxiliar no aumento do conhecimento acerca da doação de órgãos e da atuação do profissional enfermeiro, levando-o a uma atuação segura e bem informada quanto a todas as nuances que envolvem desde o diagnóstico de
6

O texto da nova lei de transplantes no Brasil trouxe diversas alterações com o intuito de agilizar o processo de doação de órgãos, desde o diagnóstico de morte encefálica até sua entrega ao receptor. Surge assim a necessidade de verificar índices

para que se possa comparar os tempos utilizados anteriormente, para com aqueles utilizados atualmente, após sua instauração, para que se possa saber se na prática os objetivos desta lei estão sendo alcançados $^{(8)}$. morte encefálica até a retirada efetiva dos órgãos.

Frente a estes fatos, questiona-se: A nova legislação para a doação de órgãos agilizará efetivamente o processo desde o diagnóstico de morte encefálica até a efetivação da doação? Objetiva-se, portanto, verificar a efetividade da agilização da doação de órgãos frente à nova legislação brasileira, tendo-se como objetivos específicos descrever a Lei de Transplante de órgãos brasileira e suas consecutivas alterações, e analisar os fatores dificultantes no processo de doação de órgãos.

\section{METODOLOGIA}

Este projeto trata-se de um estudo de revisão integrativa, método de investigação que viabiliza a busca, avaliação crítica e a síntese das evidências disponíveis sobre: A Efetividade do Processo de Doação de Órgãos frente a Nova Legislação.

Revisão integrativa é um método de pesquisa utilizado desde 1980, no âmbito da Prática Baseada em Evidências (PBE), que envolve a sistematização e publicação dos resultados de uma pesquisa bibliográfica em saúde para que possam ser úteis na assistência à saúde, acentuando a importância da pesquisa acadêmica na prática clínica. $\mathrm{O}$ principal objetivo da revisão integrativa é a integração entre a pesquisa científica e a prática profissional no âmbito da atuação profissional|(10).

Para tal, foram seguidas as seis etapas inerentes a este método, sendo: o estabelecimento da questão de pesquisa, a busca na literatura, categorização dos estudos, avaliação dos estudos incluídos na revisão, interpretação dos resultados e apresentação da revisão.

Como primeira etapa, foi definida a seguinte questão norteadora: A nova legislação para a doação de órgãos agilizará efetivamente o processo desde o diagnóstico de morte encefálica até a efetivação da doação? 
Na segunda etapa foi necessário buscar conhecimento sobre a nova legislação para a doação de órgãos. A coleta de dados se deu entre os meses de setembro a novembro de 2018. Foram selecionados artigos publicados em periódicos científicos nacionais e internacionais revisados por pares que abordassem a temática, constante no banco de dados da Biblioteca Virtual da Saúde (BVS), SciELO e LILACS; localizáveis por intermédio do descritor "Doação de Órgãos" ou da combinação entre: "Doação", "Órgãos", "Legislação" e "Enfermagem".

Foram selecionados os artigos de acordo com os seguintes critérios de inclusão: os divulgados em língua portuguesa, chamando-se a atenção que por se tratar de Lei recente o Recorte temporal mantem-se em dois anos, 2017 e 2018. Como critérios de exclusão têm-se: publicações que não se encontram disponíveis em texto completo; textos duplicados, e textos que não abordem a nova legislação.
Utilizando-se o método de análise Prisma, primeiramente buscou-se artigos com o descritor "Doação de Órgãos", obtendo-se 17.636 artigos. Logo a seguir, adicionou-se o boleador "AND" e o descritor "Legislação" obtendo-se 3.426 artigos. Incluiu-se a seguir "AND" e o descritor "Enfermagem" obtendo-se 103 artigos.

Utilizando-se o critério de inclusão de texto completo, obteve-se 22 artigos. Ao utilizar-se o recorte temporal de dois anos, obteve-se 15 artigos. Dois artigos estavam duplicados. Com a análise temática, verificou-se que três não se adequavam aos objetivos propostos. Portanto, selecionou-se 10 artigos, os quais foram analisados a seguir. Para melhor visualização do processo de busca, organizou-se o fluxograma:

$\mathrm{Na}$ terceira etapa, visando a categorização dos artigos foi efetuada a tabulação dos artigos selecionados contendo as variáveis relacionadas à identificação dos artigos: ano, autores, método, objetivos e conclusões.
Nesta etapa os artigos foram subdivididos em categorias temáticas. $\mathrm{Na}$ quarta etapa foi realizada avaliação dos estudos incluídos na revisão, com sua leitura aprofundada e retirada dos pontos principais a serem abordados. $\mathrm{Na}$ quinta etapa foi realizada análise dos resultados encontrados nos artigos selecionados.

E por fim, na sexta etapa foi apresentada a discussão das categorias em forma de artigo acadêmico relatado todo o desenrolar do processo, bem como a melhor abordagem para enfermagem frente à doação de órgãos.

\section{RESULTADOS}

Após a busca e seleção de 10 artigos, foi efetuada a tabulação dos artigos selecionados contendo as variáveis relacionadas à identificação dos artigos: ano, autores, método, objetivos e conclusões. Dos artigos foram utilizados os dos anos 2018 (4) e 2017 (6) buscando informações atualizadas e após a promulgação da nova legis-

\section{Fluxograma 1. Prisma. Rio de Janeiro, RJ, Brasil, 2017-2018}

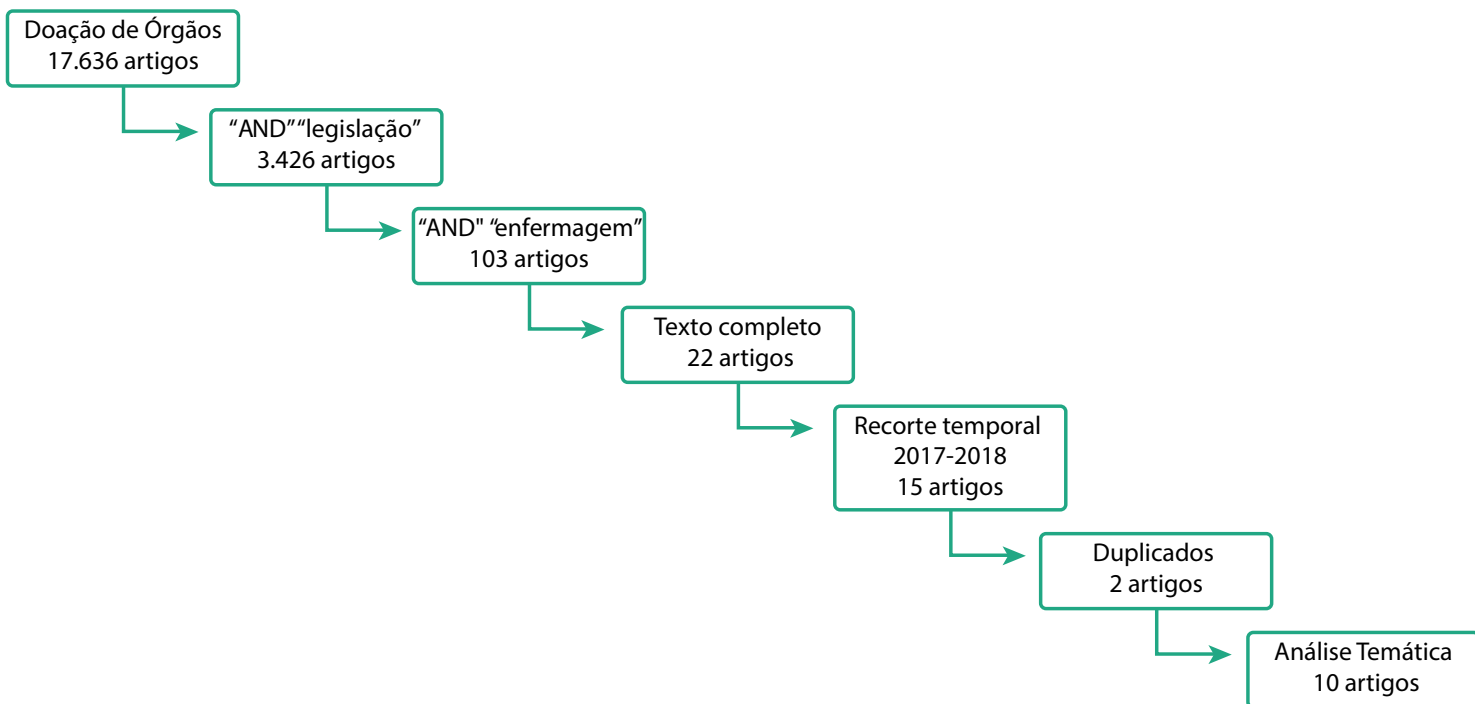


lação. Quanto à delimitação da metodologia, verificou-se que são: revisão integrativa (1), levantamento bibliográfico (2), estudo transversal (1), re- lato de experiência (1), fundamentado em dados (2), descritivo (2) e interpretativo (1). Verifica-se a existência de poucas publicações exclusivas sobre a nova legislação e suas implicações e acredita-se que se deva ao pouco tempo de sua promulgação, final do ano de 2017.

Chart 2. Care plan for patients with Fournier Syndrome. Brasilia, DF, Brazil, 2019

\begin{tabular}{|c|c|c|c|c|c|}
\hline Ano & Autor & Periódico & Método & Objetivo & Resultado \\
\hline 2018 & $\begin{array}{l}\text { Santos } \\
\text { et al. }\end{array}$ & $\begin{array}{l}\text { ABCS Health Sci. } \\
2018 ; \quad 43(1): 30- \\
35\end{array}$ & $\begin{array}{l}\text { Estudo descri- } \\
\text { tivo e qualita- } \\
\text {-tivo }\end{array}$ & $\begin{array}{l}\text { Conhecer as percep-ções das } \\
\text { pessoas sub-metidas ao trans- } \\
\text { plante renal sobre a doação de } \\
\text { órgãos. }\end{array}$ & $\begin{array}{l}\text { Os dados apresentam a manifestação sobre a ne- } \\
\text { cessidade da doação de órgãos, sendo estimulada a } \\
\text { promoção pelos meios de co-municação, ainda que } \\
\text { somente a família pos-sa optar pela doação quando } \\
\text { se depara com a morte de um ente querido, a questão } \\
\text { da compatibilidade do órgão para o receptor, o esfor- } \\
\text { ço para poder realizar a doação e o recomeçar a vida. }\end{array}$ \\
\hline 2018 & $\begin{array}{l}\text { Pauli et } \\
\text { al. }\end{array}$ & $\begin{array}{l}\text { REVISTA DE } \\
\text { ADMI-NISTRA- } \\
\text {-ÇÃO PÚ-BLICA } \\
\text { | Rio de Janeiro } \\
\text { 52(3):554-570, } \\
\text { maio - jun. } 2018\end{array}$ & $\begin{array}{l}\text { Pesquisa qua- } \\
\text { li-tativa-inter- } \\
\text { pretativa }\end{array}$ & $\begin{array}{l}\text { Analisar quais são os sím-bo- } \\
\text { los que o Sistema Nacio-nal de } \\
\text { Transplantes (STN) produz para } \\
\text { a construção de um ambiente } \\
\text { favorável à doação }\end{array}$ & $\begin{array}{l}\text { A exploração de sentimentos alternativos à ideia } \\
\text { de morte-vida e de doação como um gesto altruís- } \\
\text { ta possibilitaria a constru-ção de novas referências } \\
\text { simbólicas para a doação de órgãos. }\end{array}$ \\
\hline 2018 & $\begin{array}{l}\text { Amaral } \\
\text { et al. }\end{array}$ & $\begin{array}{l}\text { Lecturas: Edu- } \\
\text { cación Física y } \\
\text { Deportes, Vol. 23, } \\
\text { Núm. 244, Sep. } \\
\text { (2018) }\end{array}$ & $\begin{array}{l}\text { Relato de ex- } \\
\text { pe-riência }\end{array}$ & $\begin{array}{l}\text { Descrever as dificuldades exis- } \\
\text { tentes no processo de captação } \\
\text { de órgãos e teci-dos para trans- } \\
\text { plante e discutir os desafios } \\
\text { enfren-tados pela equipe da } \\
\text { CI-HDOTT }\end{array}$ & $\begin{array}{l}\text { No processo de doação existem desafios e obstá- } \\
\text { culos que impedem o funciona-mento adequado } \\
\text { do serviço, quais sejam: desafios na infraestrutura } \\
\text { do hospital, que não é adequada para o serviço, } \\
\text { desafios na equipe em relação à comunicação e co- } \\
\text { nhecimento do processo, desafios relacionados aos } \\
\text { familiares na recusa da doação de órgãos e tecidos. }\end{array}$ \\
\hline 2017 & $\begin{array}{l}\text { Bonetti } \\
\text { et al. }\end{array}$ & $\begin{array}{l}\text { Rev enferm UFPE } \\
\text { on line., Reci-fe, } \\
11 \text { (Supl. 9):3533- } \\
\text { 41, set }\end{array}$ & $\begin{array}{l}\text { Estudo descri-ti- } \\
\text { vo, transver-sal, } \\
\text { retrospecti-vo, } \\
\text { documental, } \\
\text { de abordagem } \\
\text { quantitativa, }\end{array}$ & $\begin{array}{l}\text { Descrever características do } \\
\text { processo de doação de órgãos } \\
\text { e tecidos e identifi-car fatores } \\
\text { determinantes para a sua não } \\
\text { efetivação }\end{array}$ & $\begin{array}{l}0 \text { estudo proporcionou conhecimento sobre os prin- } \\
\text { cipais motivos da não doa-ção de órgãos e tecidos do } \\
\text { paciente potencial doador, contribuindo para o desen- } \\
\text { volvimento de estratégias que po-tencializem esse pro- } \\
\text { cesso, direcionadas aos fatores modificáveis, identifica- } \\
\text { dos como sendo limitantes para a efetivação da doação. }\end{array}$ \\
\hline 2017 & $\begin{array}{l}\text { Maga- } \\
\text {-Ihães } \\
\text { et al. }\end{array}$ & $\begin{array}{l}\text { Cogitare Enferm. } \\
(22) 2 \text { : e45621, } \\
2017\end{array}$ & $\begin{array}{l}\text { Levantamento } \\
\text { bibliográfico }\end{array}$ & $\begin{array}{l}\text { Apresentar aspectos inova-do- } \\
\text { res para a prática profis-sional } \\
\text { do enfermeiro, no que se refere } \\
\text { ao diagnósti-co de morte ence- } \\
\text { fálica no processo de doação e } \\
\text { transplante de órgãos e tecidos, } \\
\text { abordando as interfaces entre a } \\
\text { gerência do cuidado e a segu- } \\
\text { rança do paciente. }\end{array}$ & $\begin{array}{l}\text { Enfatiza-se a padronização de processos, utiliza- } \\
\text { da para promover agilidade, redu-ção das perdas } \\
\text { por parada cardíaca com aumento concomitante } \\
\text { das doações reais, e diminuição do tempo entre } \\
\text { o primeiro exame clínico e o explante. Permite } \\
\text { que a equipe reconheça as anormalidades e faça } \\
\text { as correções necessárias em tempo hábil. Assim, } \\
\text { vislumbra-se que a seguran-ça do paciente deve } \\
\text { subsidiar as tomadas de decisão e intervenções de } \\
\text { gestão, de modo a qualificar a prática de cuidado. }\end{array}$ \\
\hline
\end{tabular}




\begin{tabular}{|c|c|c|c|c|c|}
\hline 2017 & $\begin{array}{l}\text { Rosat- } \\
\text { to et al. }\end{array}$ & $\begin{array}{l}\text { REME • Rev Min En- } \\
\text { ferm. 2017;21:e-1056 }\end{array}$ & $\begin{array}{l}\text { Estudo qua- } \\
\text { lita-tivo, des- } \\
\text { critivo-ex- } \\
\text { ploratório, } \\
\text { na modali- } \\
\text { dade estudo } \\
\text { de caso }\end{array}$ & $\begin{array}{l}\text { Compreender as motiva-ções } \\
\text { que influenciam as famílias } \\
\text { na decisão para a doação ou } \\
\text { não de órgãos de um familiar } \\
\text { adulto. }\end{array}$ & $\begin{array}{l}\text { Os motivos para aceitar a doação estão relaciona- } \\
\text { dos à intenção de ajudar pesso-as que precisam e } \\
\text { fazer o que o familiar os havia pedido. Destaca-se } \\
\text { a necessidade de mais estudos relacionados ao } \\
\text { proces-so vivenciado pelas famílias, em torno da } \\
\text { morte encefálica e do processo de deci-são, para } \\
\text { que seja possível compreender com mais profun- } \\
\text { didade as situações vividas por seus membros du- } \\
\text { rante esse processo. }\end{array}$ \\
\hline 2017 & $\begin{array}{l}\text { Silva et } \\
\text { al. }\end{array}$ & $\begin{array}{l}\text { J. res.: fundam. care. } \\
\text { online 2017. jul./set. } \\
\text { 9(3): 882-887 }\end{array}$ & $\begin{array}{l}\text { Revisão inte- } \\
\text {-grativa }\end{array}$ & $\begin{array}{l}\text { Identificar as produções que } \\
\text { abordam o papel do enfer- } \\
\text { meiro intensivista no con- } \\
\text { texto da morte encefáli-ca, } \\
\text { identificando seus resul-ta- } \\
\text { dos e conclusões. }\end{array}$ & $\begin{array}{l}\text { Pode-se perceber a relevância de um conhecimen- } \\
\text { to específico dos profissio-nais da saúde, princi- } \\
\text { palmente os enfer-meiros, na área de doação e } \\
\text { transplantes, bem como o limitado número de pu- } \\
\text { blica-ções sobre o tema por parte dos enfermei-ros } \\
\text { e a precária abordagem sobre doação e transplan- } \\
\text { tes nos currículos da gradua-ção. }\end{array}$ \\
\hline 2017 & $\begin{array}{l}\text { Violine } \\
\text { Haya- } \\
\text {-kawa }\end{array}$ & $\begin{array}{l}\text { Vol.29, n.3,pp.42-46 } \\
\text { (Jan - Mar 2017) Re- } \\
\text {-vista UNINGÁ }\end{array}$ & $\begin{array}{l}\text { Pe s q u i s a } \\
\text { quantitativa }\end{array}$ & $\begin{array}{l}\text { Analisar o comportamento } \\
\text { numérico entre os anos de } \\
2010 \text { e } 2015 \text { de doações de } \\
\text { órgãos na área que abrange } \\
\text { a } 15^{\circ} \text { Regional de Saúde do } \\
\text { Paraná }\end{array}$ & $\begin{array}{l}\text { Conclui-se que apesar do aumento, o número de } \\
\text { doações é muito inferior quando comparado as } \\
\text { notificações de morte encefálica, existindo assim, } \\
\text { a ne-cessidade intensificar campanhas de incenti- } \\
\text { vo a doação e investir na prepara-ção das equipes } \\
\text { envolvidas nesse pro-cesso. }\end{array}$ \\
\hline
\end{tabular}

Com a análise dos dados apresentados nos artigos pode-se categorizar as subtemáticas em: A Conduta da Enfermagem Frente ao Provável Doador, Fatores que Levam à Doação de Órgãos, Efetividade da Nova Legislação na Agilização da Doação de Órgão.

\section{DISCUSSÃO}

A Conduta da Enfermagem Frente ao Provável Doador

O Brasil é destaque mundial na coordenação e na regulamentação de transplantes de órgãos em serviços públicos. O Ministério da Saúde (MS) disponibiliza custeio para despesas relacionadas à captação de órgãos, cirurgias, tratamento de complicações, atendimento ambulatorial e fornecimento de medicamentos imunossupressores ${ }^{(11)}$.

Milhares de pessoas aguardam por um transplante de órgãos com alguma doença crônica de caráter irreversível, restando como única alternativa o transplante. Esta modalidade de tratamento consiste na substituição de um órgão ou de um tecido doente de uma pessoa (receptor) por outro sadio, de um doador vivo ou falecido, através de um procedimento cirúrgico. A reposição pode ser de órgão ou tecido, como por exemplo: coração, fígado, córneas, rins, pâncreas, ossos, medula óssea e outros. É um tratamento que traz meIhoria na qualidade de vida de milhares de pessoas ou até mesmo, como única alternativa de sobrevivência ${ }^{(12)}$.

Considerando que a legislação brasileira proíbe a venda de órgãos como forma de ampliação da oferta, as organizações públicas e privadas que compõem o SNT buscam ampliar o número de doadores por meio de campanhas publicitárias de estímulo à solidariedade e ao altruísmo social, ligando agentes economicamente orientados e atores reguladores desse comércio na adoção de estratégias que aproximam a doação de órgãos da construção de um "mercado de bens simbólicos"(13).

A realização de um transplante somente é possível a partir da doação de um órgão. O processo de doação é permeado por um conjunto de ações e de procedimentos que tem a finalidade de identificar o potencial doador e de torná-lo um doador efetivo ${ }^{(11)}$.
Envolverá cuidados com o potencial doador de órgãos e com o processo fisiopatológico da morte encefálica em detrimento da percepção do enfermeiro quanto aos cuidados ao paciente nesta condição. Destaca-se que o cuidado de enfermagem a esse paciente é essencial principalmente no manejo das alterações fisiopatológicas inerentes à morte encefálica e à monitorização hemodinâmica e, isso estará diretamente associado à efetivação da doação de órgãos ${ }^{(14)}$.

Portanto, observa-se que o processo de doação e transplante se divide em diferentes etapas, e diversos profissionais estão envolvidos, entre eles, os enfermeiros. Estes profissionais integram as equipes transplantadoras e as organizações de procura de órgãos e participam de diversas atividades determinadas pela Resolução do Conselho Federal de Enfermagem (COFEN) n. ${ }^{\circ}$ 292/2004, entre elas a de notificar as Centrais de Captação e Distribuição de Órgãos (CNNCDO) da existência de potenciais doadores, entrevistar o responsável legal do doador e fornecer informações sobre o processo e aplicar a Sistematização da Assistência de Enfermagem (SAE) ao receptor ${ }^{(9)}$. 
Verifica-se ainda que neste processo de doação existem desafios e obstáculos que impedem o funcionamento adequado do serviço, e que os estudos analisados apontam para desafios: na infraestrutura do hospital, que não é adequada para o serviço, na equipe em relação à comunicação e conhecimento do processo, e relacionados aos familiares na recusa da doação de órgãos e tecidos ${ }^{(14)}$.

As coordenações hospitalares através da Comissão Intra-Hospitalar de Doação de Órgãos e Tecidos para Transplantes (CIHDOTT) ou as Organizações de Procura de Órgãos (OPOs) são responsáveis por identificar o potencial doador até sua conversão em doador efetivo, cabe à $\mathrm{CN}$ CDO de cada estado determinar as regras a serem seguidas pelas equipes quanto ao tempo de resposta de aceitação dos órgãos, bem como de sua retirada. No Brasil, as CNCDOs são o ponto de partida para iniciar o processo de doação, a partir da notificação de morte encefálica, e são responsáveis por concluir o processo de distribuição dos órgãos e tecidos obtidos para transplante ${ }^{(15)}$.

Fatores que levam a doação ou não de órgãos

Os artigos analisados consideram que os principais fatores de doar ou não órgãos são a dificuldade de entender a morte e a dor do luto, inviabilizando a autorização, uma vez que o contexto cultural, as concepções religiosas e as fantasias criadas em cima do tema de doação constituem substrato para a representação em torno de todo o processo de transplante ${ }^{(11)}$.

A doação de órgãos e tecidos para transplante está diretamente relacionada aos valores morais, éticos e religiosos das pessoas, pois faz com que os indivíduos pensem na noção de finitude e na relação com o corpo, após a morte ${ }^{(12)}$.

São mencionadas algumas razões que levam os indivíduos a optarem por serem ou não doadores de órgãos, entre elas a religião; outros mencionam o entendimento de o corpo é apenas uma matéria, a possibilidade de ajudar outras pessoas, de proporcionar a continuidade e a qualidade de vida do receptor, de reaproveitar os próprios órgãos, a necessidade social de doação e motivos religiosos ${ }^{(13,14)}$

Portanto, torna-se necessário compreender com maior profundidade essa relação dúbia entre doação e trocas que exige repensar a própria tradição dos conceitos de doação, altruísmo e solidariedade social ${ }^{(13)}$.

Nos estudos que envolvem enfermeiros, os fatores referem-se mais à sobrecarga emocional e física, a inadequação do dimensionamento de recursos humanos na UTI, a dualidade do ser enfermeiro (a pessoa e o profissional), a falta de preparo técnico e emocional para lidar com a situação da Morte Encefálica (ME), a logística do processo de doação e a formação dos profissionais de saúde ${ }^{(14)}$.

Chama-se a atenção para a importância de haver campanhas midiáticas para a promoção da doação de órgão, ressalva o desejo de que mais pessoas sejam beneficiadas pelo transplante. Os estudos salientam ainda que somente a família poderá optar pela doação quando se depara com a morte de um ente querido e a questão da compatibilidade do órgão, pois, muitas vezes, há o desejo dos familiares serem doares vivos, mas são confrontados com a não compatibilidade do órgão para o receptor ${ }^{(11)}$.

Ainda é necessário dizer que se notou que as diferentes percepções de enfermeiros que cuidam de pacientes em ME podem afetar a chance de converter o potencial doador de órgãos em doador efetivo. Existe confusão e hesitação sobre o diagnóstico de morte encefálica a ponto de possuírem esperança na reversão do quadro do paciente. É como se esperassem por um milagre ${ }^{(14)}$.

Na prática, em diversas vezes, a não conclusão do protocolo de ME por falta da conservação adequada dos potenciais doadores. Também acontece de a equipe não notificar os óbitos à CIHDOTT para que a comissão os identifique como potencial doador. Ressalta-se também que há uma grande negatividade da família quando abordados para consentimento da doação de órgãos e tecidos para transplante ${ }^{(15)}$.

Igualmente, a criação de um ambiente favorável à doação exige das organizações envolvidas na promoção e na operacionalização do sistema de doação de órgãos um trabalho no plano simbólico, visando à criação de uma economia de exortação. Ou seja, ao caracterizar o ambiente em que ocorre a doação como uma economia de trocas simbólicas, os órgãos podem ser compreendidos como bens econômicos marcados por uma forte simbologia (morte e vida), pois operam a partir de uma dupla verdade ${ }^{(14)}$.

Observa-se que a estrutura encontrada, na maioria das vezes, diverge daquela preconizada pela Associação Brasileira de Transplante de Órgãos (ABTO), pois para conservação adequada dos órgãos para doação são necessários recursos específicos e tecnológicos de monitoração dos possíveis ${ }^{(12)}$.

Diante das diferenças estabelecidas entre o cuidado ao paciente em ME e ao paciente crítico, faz-se necessário que o enfermeiro realize a organização das práticas de cuidado em UTI. Para manter a estabilidade hemodinâmica do paciente em ME potencial doador, tanto o enfermeiro da UTI como o enfermeiro da CIHDOTT organizam as práticas de cuidado a esse paciente ${ }^{(14)}$.

Ressalta-se, ainda, a importância da capacitação de profissionais de saúde envolvidos no processo de doação, na busca de ações para diminuir a perda do potencial doador, visando elevar o número de doações e reduzir o sofrimento de pessoas ${ }^{(15)}$.

No processo de doação, a segurança está em fazer a avaliação e o cuidado ao potencial doador minuciosamente. É preconizado que esse paciente seja mantido sob cuidados intensivos, pois requer atenção profissional especializada de forma contínua, materiais específicos e tecnologias para monitorização e tratamento ${ }^{(16)}$.

Acrescenta-se que, além dos profissionais deste setor, existem os profissionais das Comissões Intra-Hospitalares de Doação de Órgãos e Tecidos para Transplantes (CIHDOTT) e da Central de Transplantes, que auxiliam na condução da avaliação 
e dos cuidados ao potencial doador. As avaliações clínicas e laboratoriais são necessárias para obtenção de um enxerto de qualidade, bem como para evitar a transmissão de enfermidades infecciosas e neoplásicas ao receptor. Estas ocorrem por meio do exame físico detalhado e análise clínica minuciosa - exames laboratoriais, como hemograma completo, eletrólitos, tipagem sanguínea; exame da função renal, pancreática, hepática, pulmonar, cardiológica; sorologias para doenças infectocontagiosas e culturas biológicas ${ }^{(14)}$.

Em relação à não doação, cabe destacar que, quando a família toma essa decisão, não quer dizer que esta tenha sido fácil, mas sim que a família encontra-se tão saturada de emoções ocasionadas por essa experiência que prefere se manter num contexto no qual se sinta mais segura, sem novas notícias ou eventos desconhecidos. Então, como estratégia para evitar mais incertezas, ela opta pela não doação. ${ }^{(17)}$

A Efetividade da Nova Legislação na Agilização da Doação de Órgãos

O Brasil possui o maior programa público de transplantes do mundo. Das cirurgias realizadas no país, 95\% são pagas pelo SUS, envolvendo mais de 1.376 equipes médicas e com gastos anuais na ordem de um bilhão de reais. Esse recurso é repassado para estabelecimentos de saúde transplantadores públicos e privados como forma de financiar o tratamento dado aos pacientes. Os custos envolvidos em cada transplante são variáveis e abarcam serviços de exames, retirada, implante, medicamentos e tratamentos pós-transplantes, incluindo custos logísticos, como transporte aéreo ${ }^{(13)}$.

Embora o percentual de doações tenha aumentado, ainda muitas famílias rejeitam a doação de órgãos de seu ente querido em morte encefálica. Isso ocorre porque no Brasil somente o familiar pode autorizar a doação, ao contrário do que ocorria antigamente, em que a autorização para a doação era indexada na carteira de identidade ${ }^{(11)}$.

Outra questão que impede melho- ra da taxa de efetivação de doações é a burocracia. No Brasil, convencionou-se realizar os ritos fúnebres logo após o óbito, o que seria dificultado pelos trâmites de doação de órgãos. Entre o diagnóstico de $M E$, a notificação da central, a comunicação das equipes de transplante, uma possível necropsia no IML e a preparação do corpo para o velório, utiliza-se muito tempo, justamente quando a dor da perda chama por resolutividade ${ }^{(17)}$.

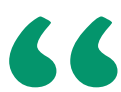

O Brasil possui o maior programa público de transplantes do mundo. Das cirurgias realizadas no país, 95\% são pagas pelo SUS, envolvendo mais de 1.376 equipes médicas $\mathrm{e}$ com gastos anuais na ordem de um bilhão de reais.

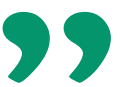

A retirada de órgãos para doação dependera da autorização da família. A legislação exige que o familiar deva ser parente de primeiro grau (filho, mãe ou pai) e é obrigatório apresentar documento comprovando o parentesco. Não se pode induzir o familiar a uma resposta, apenas falar o quanto é importante a doação de órgãos e questionar se é da sua vontade que ele seja doador. A equipe é obrigada a notificar a ocorrência do óbito e justificar a autorização ou negação da doação de órgãos e tecidos ${ }^{(14)}$.

Ainda é preocupante a crescente desproporção entre a alta demanda por transplantes de órgãos e o baixo índice de transplantes efetivados. Com isso, faz-se necessário reduzir os erros ao identificar o possível agente para a doação de órgãos e as não indicações estabelecidas pelos profissionais assistentes, seguindo as diretrizes para a avaliação e a validação do potencial doador de órgãos em morte encefálica ${ }^{(11)}$.

Com a questão da doação de órgãos e dos benefícios, muitas vezes, proporcionados para a vida do receptor, relata-se ainda sobre a necessidade de haver maior divulgação sobre o assunto ${ }^{(11)}$.

Na prática profissional, o enfermeiro, da UTI e da CIHDOTT juntamente com os demais membros da equipe de saúde devem ter conhecimento técnico e científico para garantir a manutenção da estabilidade hemodinâmica do potencial doador, possibilitando um melhor cuidado, com dignidade e respeito, de modo que ele um doador efetivo ${ }^{(14)}$.

Além disso, deve ter conhecimento do processo e a execução adequada de suas etapas possibilitando a obtenção de órgãos e tecidos com mais segurança e qualidade. A educação é fator determinante para o sucesso ou insucesso do processo de doação e transplante, sendo os treinamentos, cursos e palestras estratégias fundamentais para instrumentalizar a assistência ${ }^{(14)}$.

Apesar da nova legislação parecer ter vindo para agilizar o processo de doação de órgãos, verifica-se que a formação dos profissionais de saúde é insuficiente quanto ao preparo teórico e técnico para lidar com a morte e as reações psicoemocionais dos enlutados. O médico e a equipe precisam ter segurança na realização do diagnóstico, habilidade e sensibilidade para entender a família em seu sofrimento e comunicar a notícia de morte com a devida compreensão dos aspectos psicológicos para o acolhimento devido ${ }^{(12)}$.

Os coordenadores avançados em transplantes reconhecem e reafirmam a impor- 
tância da entrevista familiar no processo de doação, colocando-a como etapa decisiva, uma vez que é na entrevista familiar que não raro se muda uma recusa para uma autorização à doação, com o esclarecimento e orientação sobre o processo, o que confere credibilidade à equipe e aumenta a confiança dos familiares neste ato. Enfatizando-se, assim, a importância da educação permanente da equipe de saúde que realiza a abordagem da família ${ }^{(12)}$.

Vale ressaltar que a doação de órgãos é vista pela sociedade como um ato de solidariedade, mas é uma decisão tomada num momento de dor, angústia, sentimento de perda e interrupção de uma trajetória de vida, e por isso deve envolver todo o grupo familiar, para que o responsável se sinta bem com a decisão. Embora cansativo e burocrático, de maneira geral, a família se sente satisfeita com a doação, como se o ente querido estivesse continuando a fazer bem mesmo após a morte, e se dizem favoráveis à doação caso a situação se apresentasse novamente ${ }^{(18)}$.

De um modo geral, um crescente no número de doações, concluindo assim, que o trabalho das comissões tem sido satisfatório, como demonstrado nos estudos analisados. Porém, o número de doações ainda é muito inferior ao número de não doações. Ainda há muito que fazer para melhorar essa realidade, e aumentar o número doações em caso de morte encefálica, e medidas como campanhas educativas voltadas À importância da doação para conscientização da população, práticas de educação continuada para equipe multidisciplinar na abordagem familiar e manutenção do potencial doador ${ }^{(19)}$.

\section{CONCLUSÃO}

Infelizmente, devido a quase inexis- tência de pesquisas referentes à nova legislação sobre a Doação de Órgãos no Brasil, não é possível no momento, ter-se absoluta certeza quanto à sua efetividade para a agilização do processo.

Entretanto, foi possível verificar que os fatores para a não doação estão ligados a questões culturais da família do doador, a questão de infraestrutura e entraves nas instituições que fazem parte do processo e da falta de divulgação dos novos procedimentos efetuados atualmente.

Conclui-se, portanto, que mediante o apresentado, fica nítida a necessidade de verificação mais aprofundada junto aos órgãos competentes, que forneçam dados a respeito da efetivação da doação de órgãos e que aumentem o número de publicações informando e auxiliando o profissional da saúde na minimização de filas e na melhoria de qualidade de vida daquele que tanto almeja uma chance de transplante. 2

\section{Referências}

. Lima AAF, Silva MPJ, Pereira LL. Sofrimento e contradição: o significado da morte e do morrer para enfermeiros que trabalham no processo de doação de órgãos para transplante. Revista Enfermería Global. 2009 fev; 15:1-17.

. Paszczuk J. Transplantes de órgãos: um direito da personalidade. Cadernos da Escola de Direito e Relações Internacionais da UniBrasil. 2011; 15:488-509.

. Moraes EL, Santos MJ, Merighi MAB, Massarollo MCKB, Vivência de enfermeiros no processo de doação de órgãos e tecidos para transplante, Rev. Latino-Am. Enfermagem. 2014 mar.-abr.; 22(2):226-33.

. Associação Brasileira de Transplante de Orgãos (BR). [Internet] Relatório de dezembro de 2017 [acesso em 01 mai 2018]. Disponível em: http://www.abto.org.br/abtov03/Upload/file/RBT/2017/rbt-imprensa-leitura-compressed.pdf.

. G1. Temer assina decreto para alterar lei sobre doação de órgãos, informa planalto [Internet]. [acesso em 01 mar 2018]. Disponível em: https://g1.globo.com/bemestar/noticia/temer-assina-decreto-para-alterar-lei-sobre-doacao-de-orgaos-informa-planalto.html.

. Fonseca P, Tavares C, Silva I, Nascimento V. 11 Situações difíceis e seu manejo na entrevista para doação de órgãos, Revista Portuguesa de Enfermagem de Saúde Mental. 2016 out; Esp. 4.

. Brasil. Lei n. ${ }^{\circ}$ 9.434, de 4 de fevereiro de 1997 [Internet]. [acesso em 01 mar 2017]. Disponível em: http://www.planalto.gov.br/ccivil_03/leis/L9434.htm.

. Brasil. Decreto n. ${ }^{0}$ 9.175, de 18 de outubro de 2017 [Internet]. [acesso em 01 mar 2017]. Disponível em: http://www.planalto.gov. br/ccivil_03/_ato2015-2018/2017/decreto/D9175.htm.

. Conselho Federal de Enfermagem (BR). Resolução n. 292 de 2004 [Internet]. [acesso em 02 abr 2018]. Disponível em: http://www.cofen.gov.br/resoluo-cofen-2922004_4328.html.

. Mendes KDS, Silveira RCP, Galvão C. Revisão integrativa: método de pesquisa para a incorporação de evidências na saúde e na enfermagem. Texto contexto - enferm. 2008; 17(4).

. Santos BP, Viegas AC, Paula EA, Lise F, Rodrigues LPV, Fuculo Junior PRB, Schwartz E. Percepção de pessoas submetidas ao transplante renal sobre a doação de órgãos ABCS Health Sci. 2018; 43(1):30-35. 12. Amaral APS Silva JM Santana LPSantos T Anjos NVieiraSNS. Desafios encontrados no processo de doação de órgãos: relato de experiência. Lecturas: Educación Física y Deportes. 2018 Sep; 23(244). 13. Pauli J, Dalmoro M, Basso K. A economia de bens simbólicos e a criação de um ambiente favorável à doação: uma análise das campanhas de incentivo à doação de órgãos e tecidos. Revista de Administração Pública. 2018 mai.-jun.; 52(3):554-570.

14. Magalhaes ALP, Erdmann AL, Sousa FGM, Lanzoni GMM, Silva EL, Mello ALSF. Significados do cuidado de enfermagem ao paciente em morte encefálica potencial doador. Rev Gaúcha Enferm. 2018; 39:e2017- 0274.

15. Violin AR, Hayakawa LY, Doação de órgãos e tecidos: a realidade de uma regional do paraná. Revista Uningá. 2017 jan.-mar.; 29(3):42-46

16. Bonetti CE, Boes AA, Lazzari DD, Busana JA, Maestri E, Bresolin $P$ Doação de órgãos e tecidos e motivos de sua não efetivação Rev enferm UFPE on-line. 2017 set; 11(Supl. 9):3533-41.

17. Rossato GC, Girardon-Perlini NMO, Begnini D, Beuter M, Camponogara S, Flores CL. Doar ou não doar: a visão de familiares frente à doação de órgãos. REME - Rev Min Enferm. 2017

18. Magalhães ALP, Lanzoni M, Knihs NS, Silva EL, Erdmann AL, Segurança do paciente no processo de doação e transplante de órgãos e tecidos. Cogitare Enferm. 2017; (22)2:e45621.

19. Graf C. Silva OC. Doação de órgãos e transplante: um binômio a ser otimizado. Medicina (Ribeirão Preto, Online). 2017; 50(5):345-8. 